\title{
Fructooligosaccharide production by Penicillium expansum
}

\author{
Margarida B. Prata $\cdot$ Solange I. Mussatto $\cdot$ \\ Lígia R. Rodrigues $\cdot$ José A. Teixeira
}

Received: 26 November 2009/Revised: 2 February 2010/Accepted: 5 February 2010/Published online: 7 March 2010

(C) Springer Science+Business Media B.V. 2010

\begin{abstract}
Fructooligosaccharides (FOS) production by Penicillium expansum was evaluated. In a first stage, the best conditions for $P$. expansum growth and sporulation were established with potato/dextrose/ agar being the most suitable medium at between 22 and $25^{\circ} \mathrm{C}$, giving good growth and good sporulation. The inocula from this medium were used for FOS production using shake-flask cultures, and yielded $0.58 \mathrm{~g} \mathrm{FOS} / \mathrm{g}$ sucrose ( $3.25 \mathrm{~g}$ FOS/l.h), demonstrating the potential of this strain for sucrose conversion to FOS.
\end{abstract}

Keywords $\beta$-fructofuranosidases .

Fructooligosaccharides $\cdot$ Penicillium expansum

Electronic supplementary material The online version of this article (doi:10.1007/s10529-010-0231-y) contains supplementary material, which is available to authorized users.

M. B. Prata · S. I. Mussatto $(\square) \cdot$ L. R. Rodrigues · J. A. Teixeira

IBB - Institute for Biotechnology and Bioengineering, Centre of Biological Engineering, University of Minho, Campus de Gualtar, 4710-057 Braga, Portugal e-mail: solange@deb.uminho.pt; solangemussatto@hotmail.com

Present Address:

M. B. Prata

FCUP - Sciences Faculty, Department of Chemistry, University of Porto, Porto, Portugal

\section{Introduction}

Fructooligosaccharides (FOS) are non-conventional sugars that cannot be hydrolyzed by gastrointestinal enzymes. They have a low caloric value and can promote beneficial effects to the host through the selective stimulation of indigenous bacteria like bifidobacteria and lactobacilli (Mussatto and Mancilha 2007; Teitelbaum and Walker 2002). They are formed by $\beta(2 \rightarrow 1)$-linked fructose $(\mathrm{F})$ units with a last one, $\alpha(2 \rightarrow 1)$, attached to a terminal glucose $(\mathrm{G})$ moiety. These oligomers are mainly composed of 1-kestose $\left(\mathrm{GF}_{2}\right), 1$-nystose $\left(\mathrm{GF}_{3}\right)$, and 1- $\beta$-fructofuranosyl nystose $\left(\mathrm{GF}_{4}\right)$, which are found in many fruits and vegetables, although in too low a concentration to exert any beneficial effect (Yun 1996). Commercially, FOS can be produced by from sucrose using microbial $\beta$-fructosyltransferases (FTases) or $\beta$-fructofuranosidases (FFases) with high transfructosylating activity (Chen and Liu 1996). Such enzymes can be obtained from plants, bacteria or fungi, with the latter giving the greatest yields (Yun 1996; Antosová et al. 2008). Several strains, especially those from the Aspergillus genus, are good FOS producers (Sangeetha et al. 2005). However, there is no report on FOS production by Penicillium expansum. The present work, therefore, has evaluated FOS production by this fungus. Initially, the best conditions for producing an inoculum of fungal spores were established and this was then followed by an examination of FOS production in shake-flask culture. 


\section{Materials and methods}

Microorganism and culture conditions

Penicillium expansum MUM 02.14 was obtained from Micoteca of the Centre of Biological Engineering, University of Minho, Portugal. Mycelia growth and sporulation at 22 and $27^{\circ} \mathrm{C}$, in potato/dextrose/agar (PDA) and Czapek-Dox agar (CZ) media, were evaluated, in Petri dish culture. Plates were inoculated with $40 \mu \mathrm{l}$ spore suspension containing $7.5 \times 10^{7}$ spores/ml. Six plates (3 PDA and $3 \mathrm{CZ}$ ) were incubated at $22^{\circ} \mathrm{C}$ and six similar ones at $27^{\circ} \mathrm{C}$.

Fermentation medium and conditions for FOS production

FOS production was carried out in $500 \mathrm{ml}$ Erlenmeyer flasks containing $100 \mathrm{ml}$ culture medium $(\% \mathrm{w} / \mathrm{v})$ : sucrose (20), yeast extract (2.75), $\mathrm{NaNO}_{3}$ (0.2), $\mathrm{K}_{2} \mathrm{HPO}_{4}(0.5), \mathrm{MgSO}_{4} \times 7 \mathrm{H}_{2} \mathrm{O}(0.05)$, and $\mathrm{KCl}(0.05)$, sterilized at $112^{\circ} \mathrm{C}$ for $15 \mathrm{~min}$. The flasks were inoculated with $1 \mathrm{ml}$ spore suspension containing around $1.8 \times 10^{7}$ spores $/ \mathrm{ml}$, and incubated at $25^{\circ} \mathrm{C}$ with shaking at $160 \mathrm{rpm}$ for $48 \mathrm{~h}$. Experiments were carried out in duplicate; and samples were aseptically collected for determining FOS (1-kestose, 1 -nystose, and 1- $\beta$-fructofuranosyl nystose) and residual sugars (sucrose, fructose and glucose) concentrations, along with extracellular $\beta$-fructofuranosidase activity. Biomass concentration was determined at the end.

Analytical methodology

\section{Microorganism growth and sporulation}

Penicillium expansum growth in Petri plates was assessed daily for 7 days. Sporulation was determined by counting the spores in a Neubauer chamber after suspending them in $5 \mathrm{ml} 0.1 \%$ (w/v) Tween 80 . Biomass in the fermentation medium $(\mathrm{g} / \mathrm{l})$ was determined after drying at $105^{\circ} \mathrm{C}$.

\section{Sugars and fructooligosaccharides determination}

FOS and residual sugar concentration in the fermentation broth were determined by HPLC (Mussatto et al. 2009). FOS yield was calculated as the proportion of the sum of 1-kestose, 1-nystose and $1-\beta$-fructofuranosyl nystose to the initial sucrose concentration ( $\mathrm{Y}_{\mathrm{P} / \mathrm{St}}$ in $\mathrm{g} / \mathrm{g}$ ), and to consumed sucrose concentration $\left(\mathrm{Y}_{\mathrm{P} / \mathrm{Sc}}\right.$ in $\left.\mathrm{g} / \mathrm{g}\right)$. FOS productivity $\left(\mathrm{Q}_{\mathrm{P}}\right.$ in $\mathrm{g} / \mathrm{l}$.h) was calculated as the total FOS production $(\mathrm{g} / \mathrm{l})$ by fermentation time $(h)$.

\section{Enzyme activity}

Samples of the filtered fermentation broth were used as extracellular enzyme source. The $\beta$-fructofuranosidase (FFase) activity was determined by measuring the amount of glucose produced from sucrose (Yoshikawa et al. 2006).

Statistical analysis

The results were analyzed by the Tukey test using the software Statgraphics version 4.1. A $P$ value less than 0.05 indicated significant differences among samples.

\section{Results and discussion}

Growth and sporulation conditions for Penicillium expansum

Penicillium expansum grew well when at 22 and $27^{\circ} \mathrm{C}$ in both PDA and CZ media; however, the sporulation occurred only on PDA medium (as shown in Supplementary Figs. 1 and 2). At the same temperature, there was no statistically significant differences between growth in the two media (Table 1). Nonetheless, the growth was greater at $22^{\circ} \mathrm{C}$. On the other hand, sporulation was statistically different when varying the culture medium and temperature: $\mathrm{CZ}$ was less suitable than PDA for sporulation at both temperatures. Such results can be explained by the low $\mathrm{N}$ concentration in PDA medium (Supplementary Table 1).

In a final step, fungal growth and sporulation was also evaluated at $25^{\circ} \mathrm{C}$ which was similar to that at $22^{\circ} \mathrm{C}$. Therefore, PDA is suitable for good growth and sporulation of $P$. expansum between 22 and $25^{\circ} \mathrm{C}$.

Fructooligosaccharides production

Figure 1a shows the time course of sucrose consumption and FOS production by $P$. expansum grown at the previously established cultivation conditions. 
Table 1 Multiple comparison analysis of mycelial growth rate and sporulation results of Penicillium expansum cultivated in Potato Dextrose Agar (PDA) and Czapek-Dox Agar (CZ), at 22 and $27^{\circ} \mathrm{C}$

\begin{tabular}{lll}
\hline Culture media/temperature $\left({ }^{\circ} \mathrm{C}\right)$ & $\begin{array}{l}\text { Radial growth rate }(\mathrm{mm} / \mathrm{h})^{*} \\
\text { Average** }\end{array}$ & $\begin{array}{l}\text { Sporulation }\left(10^{7} \text { spores } / \mathrm{ml}\right) \\
\text { Average** }\end{array}$ \\
\hline $\mathrm{CZ} / 27$ & $0.157^{\mathrm{a}}$ & $0^{\mathrm{a}}$ \\
$\mathrm{PDA} / 27$ & $0.148^{\mathrm{a}}$ & $14^{\mathrm{b}}$ \\
$\mathrm{CZ} / 22$ & $0.242^{\mathrm{b}}$ & $3.4^{\mathrm{a}}$ \\
$\mathrm{PDA} / 22$ & $0.249^{\mathrm{b}}$ & $29^{\mathrm{c}}$ \\
\hline
\end{tabular}

* Each value was calculated as the overall average of colony diameter measurements (in 3 different directions) taken every day, during 7 days, for each of the three replicates

** Same letters denotes no statistically significant differences at $95 \%$ confidence level

There was an initial lag phase up to $12 \mathrm{~h}$ before FOS formation began. Between 12 and $24 \mathrm{~h}$, sucrose conversion to FOS commenced and in the following $12 \mathrm{~h}$, the process attained the maximum FOS production $(117.7 \mathrm{~g} / \mathrm{l})$ with almost total depletion of sucrose. Maximum production of FOS corresponded to a final product containing 1-kestose $\left(\mathrm{GF}_{2}-80 \%\right)$, 1 -nystose $\left(\mathrm{GF}_{3}-19 \%\right)$, and 1- $\beta$-fructofuranosyl nystose $\left(\mathrm{GF}_{4}-1 \%\right)$ (Fig. 1b). According to Cruz et al. (1998) FOS synthesis always occurs in the sequence $\mathrm{GF} \rightarrow \mathrm{GF}_{2} \rightarrow \mathrm{GF}_{3} \rightarrow \mathrm{GF}_{4}$, as a consequence of the increasing $\mathrm{Km}$ values for such products presented by the transfructosylase. Thus, high concentrations of the preceding oligosaccharide are necessary for the synthesis of the homolog with one more fructose unit. After $36 \mathrm{~h}$, due to sucrose exhaustion from the media, the microorganism started consuming the produced FOS and, therefore, the total FOS concentration decreased.

FOS production by $P$. expansum occurred with $\operatorname{good}$ yield $\left(\mathrm{Y}_{\mathrm{P} / \mathrm{St}}=0.58 \mathrm{~g} / \mathrm{g} ; \mathrm{Y}_{\mathrm{P} / \mathrm{Sc}}=0.68 \mathrm{~g} / \mathrm{g}\right)$ and productivity $\left(\mathrm{Q}_{\mathrm{P}}=3.25 \mathrm{~g} / \mathrm{l} \mathrm{h}\right)$ when compared to the results obtained for other producer strains like Aspergillus japonicus $\left(\mathrm{Y}_{\mathrm{P} / \mathrm{St}}=0.61 \mathrm{~g} / \mathrm{g}, \mathrm{Y}_{\mathrm{P} / \mathrm{Sc}}=0.64 \mathrm{~g} / \mathrm{g}\right.$, $\mathrm{Q}_{\mathrm{P}}=5.36 \mathrm{~g} / \mathrm{l} . \mathrm{h}$ ) (Mussatto et al. 2009), being similar to the maximum yield normally found for microorganisms (55-60\%, w/w) (Yun 1996; Nishizawa et al. 2001). Nevertheless, the values reported here can probably be improved by establishing the best conditions for performing this fermentative process.

FFase activity, responsible for sucrose conversion to FOS, increased throughout the fermentation, reaching a maximum value of $41 \mathrm{U} / \mathrm{ml}$ at the end (Fig. 2). Such a value compares well with other activities for FOS producers such as A. japonicus
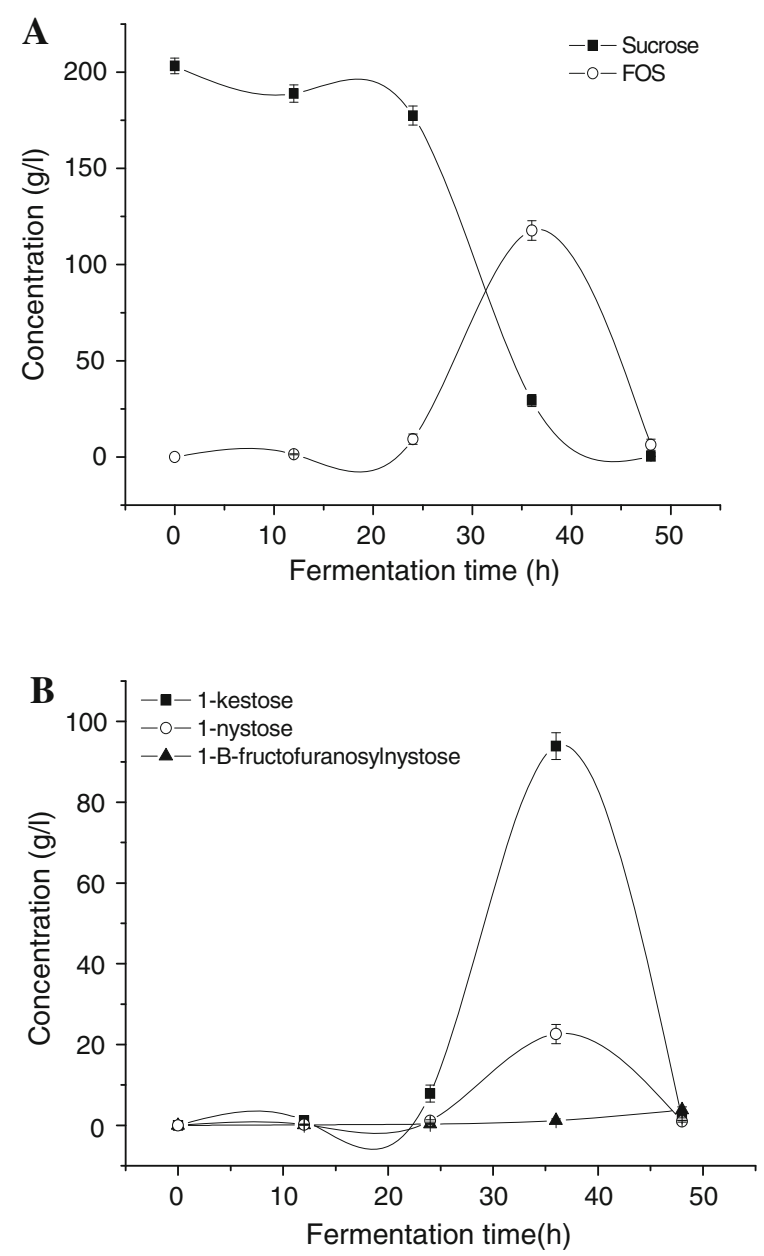

Fig. 1 Kinetic behavior of fructooligosaccharides production by Penicillium expansum using shake-flask cultures: (a) sucrose consumption and fructooligosaccharides production (as the sum of 1-kestose, 1-nystose, and 1- $\beta$-fructofuranosyl nystose); (b) 1-kestose, 1-nystose, and 1- $\beta$-fructofuranosyl nystose production 


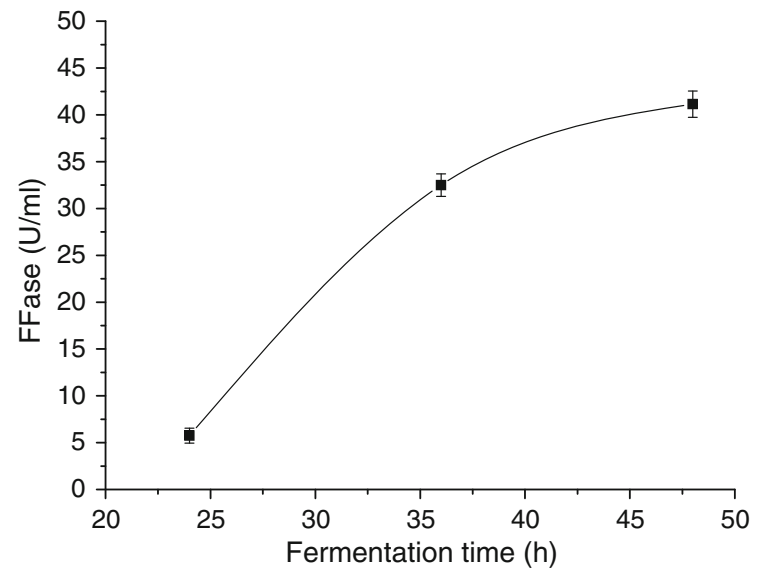

Fig. 2 Activity of $\beta$-fructofuranosidase during fructooligosaccharide production from sucrose by Penicillium expansum using shake-flask cultures

(55 U/ml) (Wang and Zhou 2006), A. japonicus (46 U/ml) (Mussatto et al. 2009), and a mutant Saccharomyces cerevisiae ( $46 \mathrm{U} / \mathrm{ml}$ ) (ul-Haq et al. 2008).

In conclusion, $P$. expansum has potential for sucrose conversion to FOS. The present results can probably be improved by establishing the best conditions for the fermentation process. Nevertheless, since this is the first study on the FOS production by $P$. expansum, the obtained results open up possibilities to develop an efficient process for producing FOS with yields higher than that usually found in batch processes (55-60\%, w/w) (Yun 1996), which is the main challenge for the FOS industries nowadays.

Acknowledgement The financial support from FCT, the Portuguese Foundation for Science and Technology (research project SFRH/BPD/38212/2007) is gratefully acknowledged.

\section{References}

Antosová M, Illeová V, Vandáková M, Druzkovská A, Polakovic M (2008) Chromatographic separation and kinetic properties of fructosyltransferase from Aureobasidium pullulans. J Biotechnol 135:58-63

Chen WC, Liu CH (1996) Production of $\beta$-fructofuranosidase by Aspergillus japonicus. Enzyme Microb Tech 18:153-160

Cruz R, Cruz VD, Belini MZ, Belote JG, Vieira CR (1998) Production of fructooligosaccharides by the mycelia of Aspergillus japonicus immobilized in calcium alginate. Bioresour Technol 65:139-143

Mussatto SI, Mancilha IM (2007) Non-digestible oligosaccharides: a review. Carbohyd Polym 68:587-597

Mussatto SI, Aguilar CN, Rodrigues LR, Teixeira JA (2009) Fructooligosaccharides and $\beta$-fructofuranosidase production by Aspergillus japonicus immobilized on lignocellulosic materials. J Mol Catal B-Enzym 59:76-81

Nishizawa K, Nakajima M, Nabetani H (2001) Kinetic study on transfructosylation by beta-fructofuranosidase from Aspergillus niger ATCC 20611 and availability of a membrane reactor for fructooligosaccharide production. Food Sci Technol Res 7:39-44

Sangeetha PT, Ramesh MN, Prapulla SG (2005) Recent trends in the microbial production, analysis and application of fructooligosaccharides. Trends Food Sci Tech 16:442-457

Teitelbaum JE, Walker WA (2002) Nutritional impact of preand probiotics as protective gastrointestinal organisms. Annu Rev Nutr 22:107-138

ul-Haq I, Ali S, Aslam A, Qadeer MA (2008) Biosyntheses of L-DOPA by Aspergillus oryzae. Bioresour Technol 99: $7-12$

Wang L-M, Zhou H-M (2006) Isolation and identification of a novel Aspergillus japonicus JN19 producing -fructofuranosidase and characterization of the enzyme. J Food Biochem 30:641-658

Yoshikawa J, Amachi S, Shinoyama H, Fujii T (2006) Multiple $\beta$-fructofuranosidases by Aureobasidium pullulans DSM2404 and their roles in fructooligosaccharide production. FEMS Microbiol Lett 265:159-163

Yun JW (1996) Fructooligosaccharides-occurrence, preparation, and application. Enzyme Microb Tech 19:107-117 